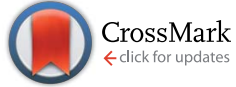

Cite this: J. Mater. Chem. C, 2015, 3, 1716

Received 4th November 2014 Accepted 17th December 2014

DOI: $10.1039 / \mathrm{c} 4 \mathrm{tc} 02510 \mathrm{e}$

www.rsc.org/MaterialsC

\section{Formation of nanoscopic $\mathrm{CaF}_{2}$ via a fluorolytic sol- gel process for antireflective coatings $\uparrow$}

\begin{abstract}
Alexander Rehmer, Kerstin Scheurell and Erhard Kemnitz*
The synthesis of nanoscopic calcium fluoride was performed by the fluorolytic sol-gel process. Antireflective coatings of $\mathrm{CaF}_{2}$ were prepared from sols obtained by the reaction of $\mathrm{CaCl}_{2}$ with $\mathrm{HF}$ and subsequent dip coating. The addition of tetramethyl orthosilicate (TMOS) or tetraethyl orthosilicate (TEOS) after fluorination promotes the formation of transparent sols. The formation and crystallisation of $\mathrm{CaF}_{2}$ nanoparticles was studied by ${ }^{19} \mathrm{~F}$ liquid and solid state NMR spectroscopy, dynamic light scattering (DLS) and X-ray powder diffraction (XRD). The morphology of a $\mathrm{CaF}_{2}$-film was analysed by high resolution scanning electron microscopy (HR-SEM) and the mechanical stability of a $\mathrm{CaF}_{2}$-film was evaluated by the Crockmeter test using both felt and steel wool. The refractive index for a $\mathrm{CaF}_{2}$-film was measured by ellipsometry. The synthesis of $\mathrm{CaF}_{2}$ nanoparticles derived from $\mathrm{CaCl}_{2}$ is a good way to achieve porous antireflective coating layers.
\end{abstract}

\section{Introduction}

Calcium fluoride and other metal fluorides exhibit superior optical properties. Their optical transmittance ranges from low UV up to the high IR region. For example, calcium fluoride is a dielectric material with an optical window ranging from 0.13 to $10 \mu \mathrm{m}$ (ref. 1) exhibiting a broad spectrum of optical applications like IR, UV, microscope, astronomical instrumentation and spectroscopy. Especially the use of calcium fluoride as ceramic material for laser applications is advantageous because not only the mechanical and optical properties compared with single crystals of calcium fluoride are better but it can be produced in large volumes. ${ }^{2-4}$ Furthermore, calcium fluoride and magnesium fluoride own a low refractive index $\left(\mathrm{CaF}_{2}: n=\right.$ 1.44 at $500 \mathrm{~nm} \mathrm{MgF}: n=1.38$ at $500 \mathrm{~nm}) .{ }^{1,5}$ Thus, calcium fluoride and magnesium fluoride are promising candidates for antireflective (AR) coatings. If the refractive index of the coating is lower than the refractive index of the substrate, the reflection of the light will decrease. The complete anti-reflection for single coatings depends on the mean geometric refractive index of the AR-layer with $n_{1}{ }^{2}=n_{\mathrm{s}} n_{0}$ and its thickness with $n_{1} d=\lambda / 4$, where $n_{1}, n_{\mathrm{S}}$ and $n_{0}$ are the refractive indices of the coating, substrate and air, respectively, $d$ the thickness of the film and $\lambda$ the wavelength of the light. ${ }^{6}$ For example, common glass mainly built up by $\mathrm{SiO}_{2}\left(n_{\mathrm{S}}=1.55\right.$ at $\left.500 \mathrm{~nm}\right)$ usually is surrounded by the medium air $\left(n_{0}=1.0\right)$. Hence, the optimum refractive index is $n_{1}=1.22$. For destructive interference, the antireflective

Humboldt-Universität zu Berlin, Department of Chemistry, Brook-Taylor-Str. 2, 12489 Berlin, Germany. E-mail: erhard.kemnitz@chemie.hu-berlin.de; Fax: +49 302093 7277

$\dagger$ Electronic supplementary information (ESI) available. See DOI: 10.1039/c4tc02510e coating is one quarter of the wavelength of light. In this case, the thickness of the AR-layer should be $102 \mathrm{~nm}$. Thus, $\mathrm{CaF}_{2}$ is a good candidate to decrease the reflection of the incident light of glass. A comparison between $\mathrm{CaF}_{2}$ and $\mathrm{MgF}_{2}$ shows similar optical properties. Only the solubility in water reveals that $\mathrm{CaF}_{2}$ $\left(16 \mathrm{mg} \mathrm{L}^{-1}\right)$ is less soluble than $\mathrm{MgF}_{2}\left(76 \mathrm{mg} \mathrm{L}^{-1}\right) .^{7}$ This is a factor, which could be interesting for the chemical resistance of an AR-layer against outdoor conditions like rain or moisture. Due to its very low solubility, $\mathrm{CaF}_{2}$-films could be more weatherproof than $\mathrm{MgF}_{2}$-films.

It is well known, that porous antireflective alkaline earth metal fluoride films can be prepared by spin coating from sols of calcium trifluoroacetate. ${ }^{8}$ That is, calcium trifluoroacetate sols in water/isopropanol are first prepared by reacting trifluoroacetic acid and calcium acetate. From the sols obtained this way a surface layer of calcium trifluorocacetate can be created by spin coating. The following annealing initiates the thermal decomposition of the trifluoroacetate resulting in a porous calcium fluoride layer as reported in J. Sol-Gel Sci. Technol. ${ }^{9}$ The disadvantage of this method is the thermal decomposition of the metal trifluoroacetates into toxic and corrosive reaction products like $\mathrm{CF}_{3} \mathrm{COF}, \mathrm{COF}_{2}$ and $\mathrm{HF}$. Another point is that a mixture of metal acetate and trifluoroacetic acid may yield metal oxide fluoride phases leading to an increase of the refractive index due to the oxygen content inside the film.

In this paper, we present an easy synthesis approach toward nanoscaled $\mathrm{CaF}_{2}$-sols via the fluorolytic sol-gel process to fabricate finally antireflective $\mathrm{CaF}_{2}$-films by dip-coating. For excellent AR-layers, it is necessary to start from a transparent sol with particle sizes of about 10 to $20 \mathrm{~nm}$ or smaller. The choice of the solvent is an important factor because only volatile solvents 
like e.g. methanol, ethanol, and isopropanol lead to homogeneous layers.

Here, we report a way to use the cost-efficient synthesis of calcium fluoride sols with commercially available calcium chloride precursors by reaction with anhydrous HF. The influence of TMOS to the calcium fluoride sol is investigated as well as the optical and mechanical properties of the calcium fluoride films obtained from thus prepared $\mathrm{CaF}_{2}$-sols.

\section{Experimental}

\section{Precursor synthesis}

All chemicals for the synthesis of calcium fluoride are commercially available and need no drying or further processing. The $19.84 \mathrm{M}$ HF-solution was prepared by dissolving anhydrous HF in ethanol.

A series of under-stoichiometric calcium fluoride sols with fluorine to calcium ratios $\mathrm{F}: \mathrm{Ca}<2$ was prepared by dissolution of $1.33 \mathrm{~g}$ anhydrous $\mathrm{CaCl}_{2}$ (96\% ABCR, $12 \mathrm{mmol}$ ) in ethanol (99.8\%, ROTH, $0.4 \mathrm{M}$ solution). Under vigorous stirring at ambient conditions, the required amount of HF-solution was added dropwise to the solution.

The stoichiometric calcium fluoride sol $(\mathrm{Ca}: \mathrm{F}=1: 2)$ for coating on glass slides (Borosilicate) was prepared by the reaction of $8.88 \mathrm{~g}$ of $\mathrm{CaCl}_{2}(80 \mathrm{mmol})$ with $8 \mathrm{~mL}$ of $\mathrm{HF}(160 \mathrm{mmol} ; 2$ eq.) in $192 \mathrm{~mL}$ ethanol. After fluorination $0.59 \mathrm{~mL}$ of TMOS (5 mol\% of Ca) respectively $0.88 \mathrm{~mL}$ of TEOS ( $5 \mathrm{~mol} \%$ of Ca) was added. The influence of TMOS was studied by ${ }^{19} \mathrm{~F}$ NMR.

\section{Deposition of $\mathrm{CaF}_{2}$ coating films}

A typical procedure for the deposition of calcium fluoride coating films was as follows. The freshly prepared calcium fluoride sols were deposited on borosilicate glass by dipcoating. Before the coating experiment the glass slides were cleaned in an alkaline solution (RBS®50) for $15 \mathrm{~min}$. The substrates were rinsed with deionized water and dried by blowing compressed air. After the coating, the substrates were calcined in a vented air-oven (Barnstead Thermolyne type F48000) at $500{ }^{\circ} \mathrm{C}$ for $15 \mathrm{~min}$ followed by slow cooling down to room temperature.

\section{Materials characterization}

The calcium fluoride sols were characterized by dynamic light scattering (DLS) and ${ }^{19} \mathrm{~F}$ liquid NMR spectroscopy. The DLS measurements were performed using a Zetasizer Nano ZS (Malvern instruments, Worcestershire, UK) using disposable PMMA cuvettes. Hydrodynamic diameters were calculated from the correlation functions by the Malvern Nanosizer Software. The viscosity was determined simultaneously to DLS measurements with a microviscometer from Anton Paar (AMVn, Graz, Austria) at $25{ }^{\circ} \mathrm{C}$. The ${ }^{19} \mathrm{~F}$ NMR spectra of the sols with varying fluorine content were carried out using a Bruker AVANCE II 300 (liquid state NMR spectrometer with a Larmor frequency of 282.4 $\mathrm{MHz}$ ). The ${ }^{19} \mathrm{~F}$ isotropic chemical shifts are given with respect to the $\mathrm{CFCl}_{3}$ standard.
The Transmission Electron Microscope (TEM) analysis has been carried out using a Philips CM200 $\mathrm{LaB}_{6}$ microscope operating at $200 \mathrm{kV}$. A few drops of the solution containing the nanoparticles have been deposited on a carbon-coated copper grid and let them dry prior to the inspection.

The calcium fluoride xerogels were characterized by an X-ray powder diffractometer from Seifert (XRD $3003 \mathrm{TT}$ ) and by ${ }^{19} \mathrm{~F}$ solid state NMR spectroscopy. The static ${ }^{19} \mathrm{~F}$ solid state NMR spectra were recorded with a Bruker AVANCE 400 (solid state spectrometer, Larmor frequency of $376.4 \mathrm{MHz}$ ) with a $4 \mathrm{~mm}$ Bruker probe and the ${ }^{19} \mathrm{~F}$ MAS NMR spectra were recorded with a $2.5 \mathrm{~mm}$ Bruker probe. The ${ }^{19} \mathrm{~F}$ isotropic chemical shifts are given with respect to $\mathrm{C}_{6} \mathrm{~F}_{6}$ as secondary standard with $\delta_{\text {iso }}=$ -166.6 ppm against $\mathrm{CFCl}_{3}$. Rotor-synchronized Hahn spin-echo experiments (rs-echo) were performed which react sensitive on homonuclear dipolar couplings. This means that fluorine species with an effective spin exchange (short spin-spin relaxation times $T_{2}$, i.e. well-bridged species) are not or with decreased intensity detected after applying longer dipolar evolution times, whereas those with longer spin-spin relaxation times (not well-incorporated, terminal) are detected. The number of rotor periods before echo detection (L0) is given in the figure captions. The percentage of chloride in the xerogels was determined by elemental analysis.

The surfaces of calcium fluoride films were examined by high-resolution scanning electron microscopy (HR-SEM) from Zeiss (Supra 40). The refractive index $n_{(500 \mathrm{~nm})}$ and thickness $t$ of the $\mathrm{CaF}_{2}$-layers was determined by spectroscopic ellipsometry. The ellipsometric parameters psi and delta were measured with a SENpro instrument (Sentech, Berlin, Germany) with the software "SpectraRay3". The calculated parameters psi and delta are determined with a Sellmeier model. The reflection and absorption of the $\mathrm{CaF}_{2}$-film was measured with an UV-Visspectrometer (Shimadzu UV-3100, Kyoto, Japan), in the range of 300-1400 nm.

The mechanic stability of the $\mathrm{CaF}_{2}$-films was tested by a crockmeter from Erichsen (scratchmarker 249) using felt and steel wool with a fineness of 0000 . The stamp with a contact area of $4.5 \mathrm{~cm}^{2}$ was pressed on the sample with a force of $4 \mathrm{~N}$.

\section{Results and discussion}

The fluorolytic sol-gel synthesis consists of the reaction between a suitable metal precursor and anhydrous hydrogen fluoride in a suitable organic solvent, preferentially methanol or ethanol. ${ }^{10}$ Several calcium precursors like $\mathrm{Ca}(\mathrm{OMe})_{2}, \mathrm{Ca}(\mathrm{OEt})_{2}$, $\mathrm{Ca}(\mathrm{OAc})_{2}$ and $\mathrm{CaCl}_{2}$ were investigated. In most of the cases, metal alkoxides like $\mathrm{Si}(\mathrm{OMe})_{4}, \operatorname{Ti}\left(\mathrm{O}^{i} \operatorname{Pr}\right)_{4}$ and $\mathrm{Al}\left(\mathrm{O}^{i} \operatorname{Pr}\right)_{3}$ or $\mathrm{Mg}(\mathrm{OMe})_{2}$, respectively, are used in the classical oxide sol-gel route. ${ }^{11-14}$ In case of the fluorolytic sol-gel synthesis, the synthesis of transparent $\mathrm{CaF}_{2}$ sols starting from calcium alkoxides is not recommended because of the insolubility of the calcium alkoxide in methanol and ethanol at room temperature. Thus, $\mathrm{Ca}(\mathrm{OMe})_{2}$ and $\mathrm{Ca}(\mathrm{OEt})_{2}$ always form crystalline white precipitates of their $\mathrm{Ca}(\mathrm{OR})_{2} \cdot 4 \mathrm{ROH}$ solvates. By subsequent de-solvation fine crystalline powders with a threedimensional polymeric structure of the $\mathrm{CdI}_{2}$ type are formed. ${ }^{15}$ 
Unfortunately, it is impossible to obtain transparent $\mathrm{CaF}_{2}$-sols under these circumstances; however, starting from calcium acetate suspended in an ethanol/acetic acid solution results in the formation of transparent $\mathrm{CaF}_{2}$-sols but the stability of these sols is poor. That means, after a few days the $\mathrm{CaF}_{2}$-sol is completely transformed to a gel. The reason for strong gelation tendency is esterification of acetic acid with the corresponding alcohol and the release of water. The more water is formed in the system the faster gelation occurs (eqn (1)).

$$
\mathrm{AcOH}+\mathrm{ROH} \rightleftarrows \mathrm{AcOR}+\mathrm{H}_{2} \mathrm{O}
$$

In spite of the gelation, coatings from these sols are possible for a short time only. The optical properties of such coatings are good but the mechanical properties are very poor due the high porosity in the film. ${ }^{16}$ Thus, calcium acetate as precursor for calcium fluoride coatings is not recommended. Therefore, we decided to use calcium chloride as precursor instead because of its good solubility in alcohol and the absence of an esterification reaction. Following the general synthesis approach of $\mathrm{MgF}_{2}$-sols via the fluorolytic sol-gel route by reacting $\mathrm{MgCl}_{2}$ in EtOH with anhydrous $\mathrm{HF},{ }^{17}$ we started from $\mathrm{CaCl}_{2}$ in $\mathrm{EtOH}$ and reacted it with ethanolic $\mathrm{HF}$ solution to form nanoscopic calcium fluoride sols (eqn (2)).

$$
\mathrm{CaCl}_{2}+2 \mathrm{HF}_{\mathrm{EtOH}} \rightarrow \text { nano } \mathrm{CaF}_{2}+2 \mathrm{HCL}
$$

The transparency of the $\mathrm{CaF}_{2}$-sol is opaque. By addition of 5 mol\% tetramethyl orthosilicate (TMOS) or tetraethyl orthosilicate (TEOS) after fluorination the former opaque sol turned into a transparent $\mathrm{CaF}_{2}$-sol. The reaction of $\mathrm{CaCl}_{2}$ in ethanol with two equivalents of ethanolic HF solution leads to the formation of nanoscopic $\mathrm{CaF}_{2}$ particles. For good optical and mechanical properties of an AR-layer the sol should be transparent to achieve a homogenous layer on the substrate. Beside sol-transparency as an indication for homodispersed nano-particle distribution, volatility of the solvent is a further pre-condition to obtain homogeneous coatings. The higher the volatility of the solvent is, the faster a homogenous film is formed. Although methanol is more volatile than ethanol, it is toxic compared to ethanol. Hence, the latter was used in all experiments. The formation of calcium fluoride nanoparticles was investigated by ${ }^{19}$ F NMR spectroscopy. The amount of HF to calcium chloride was varied from $0.1: 1$ to $2: 1$ in order to follow species that might be formed in the course of reaction. The ${ }^{19} \mathrm{~F}$ NMR spectra of the sols with different amount of HF are listed in Fig. 1. For a better illustration of the spectra without the known background signal in the ${ }^{19} \mathrm{~F}$ liquid NMR, the samples were measured statically by solid state NMR. The liquid ${ }^{19} \mathrm{~F}$ NMR spectra are included in the ESI. $\dagger$ Fig. 1 shows the typical signal for calcium fluoride at $-108 \mathrm{ppm}$. Additionally to the $\mathrm{CaF}_{2}$ signal a second broad signal appears at about $-95 \mathrm{ppm}$ and $-93 \mathrm{ppm}$ in the ${ }^{19} \mathrm{~F}$ liquid NMR, respectively. We speculated, it may stand for another calcium fluoride species like calcium chloride fluoride (CaClF) or calcium alkoxide fluoride $\left(\mathrm{CaF}_{2-x} \mathrm{OR}_{x}\right)$, which could be a solvated species. For further information of this species ${ }^{19} \mathrm{~F}$ solid state NMR and XRD measurements of the xerogels were

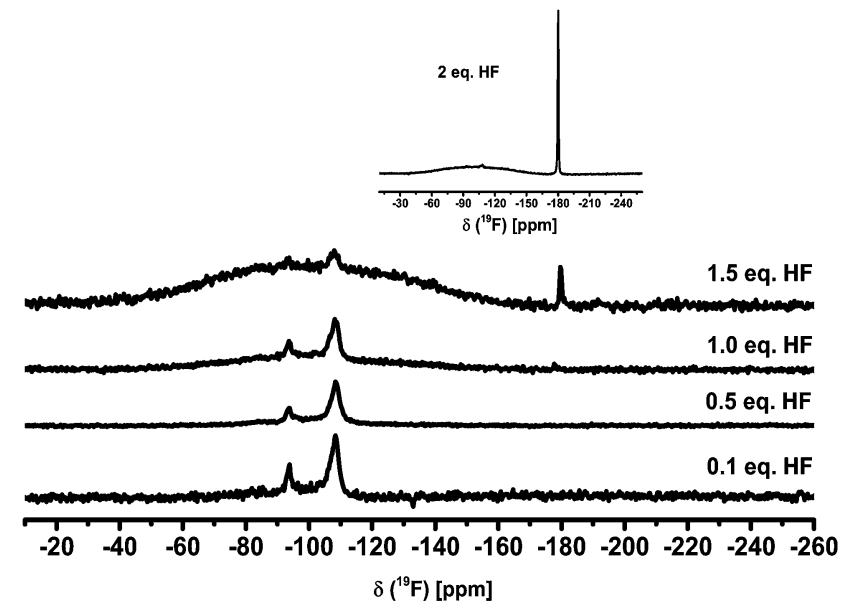

Fig. $1{ }^{19} \mathrm{~F}$ NMR spectra of the sols with different fluorine content (normalized to the $\mathrm{CaF}_{2}$ signal) carried out with ss-NMR spectrometer.

performed. Furthermore, the reaction of $\mathrm{CaCl}_{2}$ with two equivalents of $\mathrm{HF}$ exhibits a broad signal in the static solid state ${ }^{19} \mathrm{~F}$ NMR as well as in the liquid ${ }^{19} \mathrm{~F}$ NMR at about $-180 \mathrm{ppm}$ (line width $\sim 2000 \mathrm{~Hz}$ ). Samples with under-stoichiometric amounts of fluorine also contain a signal between $-174 \mathrm{ppm}$ and -180 ppm in the liquid NMR. This signal corresponds to unreacted HF adsorbed to the particle surface. ${ }^{18,19}$ A similar observation was made in the synthesis of $\mathrm{MgF}_{2}$ via the fluorolytic sol-gel route, with either $\mathrm{Mg}(\mathrm{OMe})_{2}$ or $\mathrm{MgCl}_{2}$ as reaction. Thus, we speculate that this corresponds to $\mathrm{HF}$ adsorbed at the precursor. ${ }^{17}$ During ageing of the $\mathrm{MgF}_{2}$-sol the signal vanishes.

The addition of TMOS or TEOS to the $\mathrm{CaF}_{2}$-Sol vanishes this signal completely in a short time. The formation of $\mathrm{SiOR}_{4-x} \mathrm{~F}_{x}$ and $\mathrm{SiF}_{6}{ }^{2-}$ species (the second broad signal around $-128 \mathrm{ppm}$ could be $\mathrm{CaSiF}_{6}$ (Fig. 2)) after TMOS/TEOS addition are further evidences for unreacted $\mathrm{HF}$ in the sols at this stage of nanoparticles surface causes agglomeration, but consequently, removal of this leads to clear sols. Due to the line width of $\sim 4000 \mathrm{~Hz}$ the sol consists not only of calcium fluoride particles but also of calcium hexafluorosilicate or other fluorosilicate

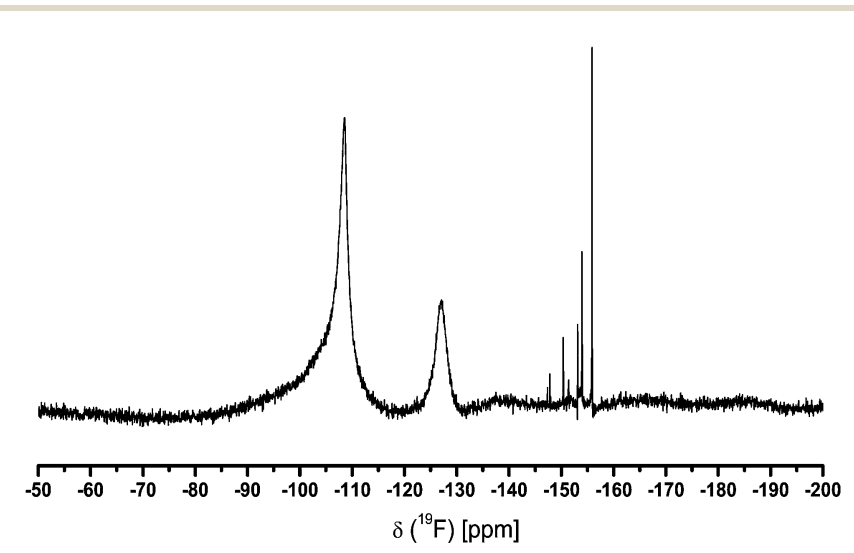

Fig. $2{ }^{19} \mathrm{~F}$ NMR spectrum of a $\mathrm{CaF}_{2}$-sol with $5 \mathrm{~mol} \%$ of TMOS. Two broad signals at $-108 \mathrm{ppm}\left(\mathrm{CaF}_{2}\right)$ and $-128 \mathrm{ppm}\left(\mathrm{SiF}_{6}{ }^{2-}, \mathrm{SiF}_{x}\right)$ are observed. No evidence for adsorbed HF (liquid NMR spectrometer). 
particles. The other small signals with line width of about 100 $\mathrm{Hz}$ are probably dissolved $\mathrm{SiOR}_{4-x} \mathrm{~F}_{x}$ species. Both species evidently are formed from unreacted $\mathrm{HF}$ and added $\mathrm{Si}(\mathrm{OMe})_{4}$. All as-prepared $\mathrm{CaF}_{2}$-sols with 5 mol\% TMOS or TEOS are transparent and possess low viscosity. Without addition of TMOS or TEOS the sol remains turbid and tends to form a gel. After a few days the particles are aggregated, that a settle to the bottom of the flask is observed, which is referred to as sedimentation of the sol. According to Fig. 3 the mean particle diameter of a sol with $5 \mathrm{~mol} \%$ TMOS was determined by dynamic light scattering. The intensity weighted particle distribution shows two size classes with mean particle diameters of $20 \mathrm{~nm}$ and $320 \mathrm{~nm}$. Due to the Stokes-Einstein relation bigger particles scatter much more than smaller particles because the intensity of scattering is proportional to the sixth magnitude of its diameter (Rayleigh approximation). It follows that small particles are significantly under-estimated. Hence, calculating the volume weighted particle distribution from intensity weighted one shows that in fact just one class of particles with a mean particle diameter of approximately $10 \mathrm{~nm}$ is present. In addition, the particle size was also investigated by transmission electron microscopy and results are included in the ESI. $\dagger$ For the identification of species with the characteristic ${ }^{19} \mathrm{~F}$ NMR signal between -93 to $-95 \mathrm{ppm}{ }^{19} \mathrm{~F}$ solid state NMR measurements were performed. For an exact identification of the unknown species, the $\mathrm{CaF}_{2}$-sol without the addition of TMOS was dried at room temperature in air and calcined at $600{ }^{\circ} \mathrm{C}$ in an electric furnace. The samples were compared with crystalline $\mathrm{CaClF}$, which was synthesized by solid state reaction between $\mathrm{CaCl}_{2}$ and $\mathrm{CaF}_{2}$ in presence of $\mathrm{NH}_{4} \mathrm{Cl}$ as flux at $730{ }^{\circ} \mathrm{C}$ for $3 \mathrm{~h}$ in an electric furnace. Wenz et al. reported an eutectic point at $645{ }^{\circ} \mathrm{C}$ for a composition of $18.5 \mathrm{~mol}^{\circ} \mathrm{CaCl}_{2}$ and 81.5 mol\% $\mathrm{CaF}_{2} \cdot{ }^{20}$ Fig. 4 shows the ${ }^{19} \mathrm{~F}$ MAS signal of the crystalline $\mathrm{CaClF}$ compound with a chemical shift of $-83 \mathrm{ppm}$. The difference between the CaClF shift and the shift of the unknown species is about $12 \mathrm{ppm}$. Hence, the unknown species does not correspond to CaClF. The most plausible explanation is that this signal corresponds to an oxide fluoride species, which
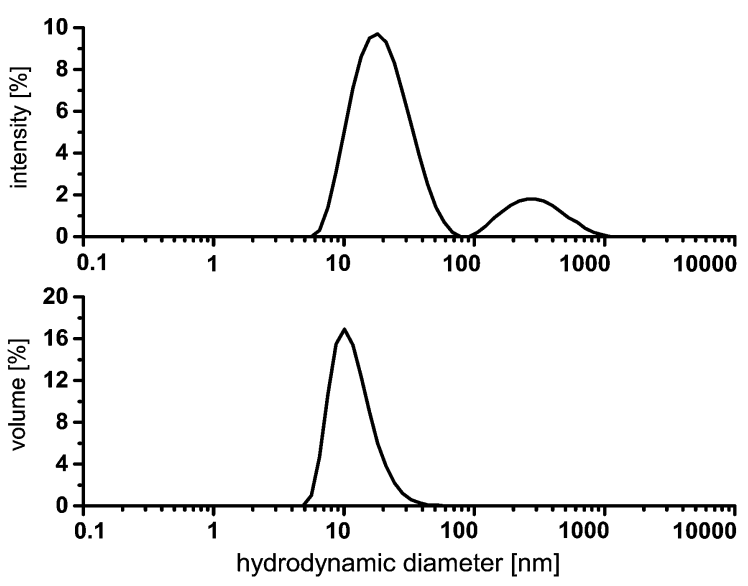

Fig. 3 Hydrodynamic diameter of particles of $\mathrm{CaF}_{2}$-sol with $5 \mathrm{~mol} \%$ TMOS measured by dynamic light scattering (intensity and volume weighted particle distribution).

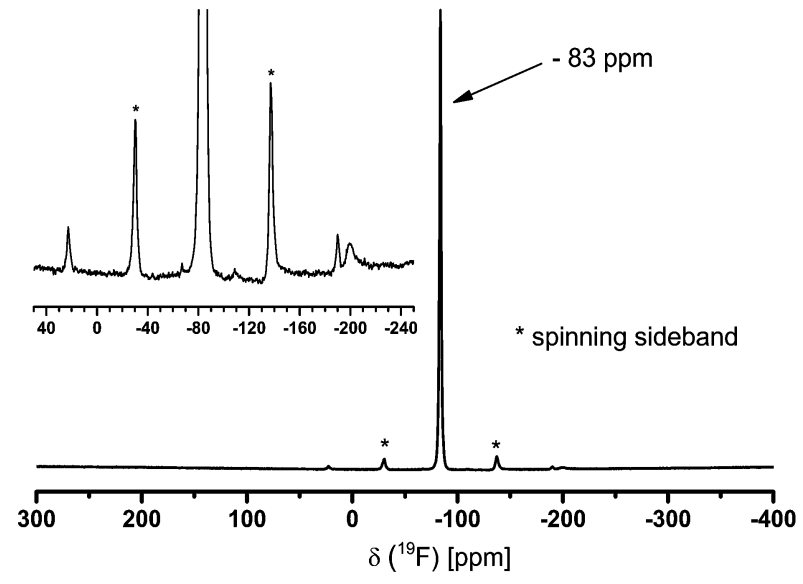

Fig. $4{ }^{19} \mathrm{~F}$ MAS NMR spectrum $\left(\nu_{\text {rot }}=20 \mathrm{kHz}\right)$ of crystalline $\mathrm{CaClF}$ (rorisite) prepared from 40 mol\% $\mathrm{CaCl}_{2}$ and $60 \mathrm{~mol} \% \mathrm{CaF}_{2}$ with $\mathrm{NH}_{4} \mathrm{Cl}$ as flux at $730{ }^{\circ} \mathrm{C}$ for $3 \mathrm{~h}$.

probably is caused by a preferential oxygen donation in the second coordination sphere as was also found for the $\mathrm{MgF}_{2}$ system. ${ }^{18}$ For comparison, the annealed $\mathrm{CaF}_{2}$ xerogel with one equivalent of $\mathrm{HF}$ shows a decrease of the signal at $-95 \mathrm{ppm}$ and an increase of the signal at $-83 \mathrm{ppm}$ in the spectrum unlike the un-annealed sample (Fig. 5). Thus, the formation of CaClF in the sol for the system $\mathrm{CaCl}_{2}$ in EtOH can be ruled out, it will only be formed at high temperature. Furthermore, the ${ }^{19} \mathrm{~F}$ signal at about -95 ppm also appears in the NMR spectra of $\mathrm{CaF}_{2}$-xerogels that have been prepared from other calcium precursors like $\mathrm{CaBr}_{2} \cdot \mathrm{H}_{2} \mathrm{O}$ and $\mathrm{CaO}$ which do not contain any chloride. The NMR spectra are listed in the ESI (Fig. S1-S3†). In the ${ }^{19} \mathrm{~F}$ ssNMR spectrum of the $\mathrm{CaF}_{2}$-xerogel obtained from $\mathrm{CaO}$ with two equivalents of $\mathrm{HF}$ appears the corresponding signal as shoulder of the main signal of $\mathrm{CaF}_{2}$. The difference between the signal shapes in the $\mathrm{CaO}-\mathrm{HF}$ system and the $\mathrm{CaCl}_{2} / \mathrm{CaBr}_{2}-\mathrm{HF}$ system might be caused by dipole-dipole coupling. The shorter the dipole-dipole coupling is, the more is the signal separated from the main signal. Another interesting fact is also the different
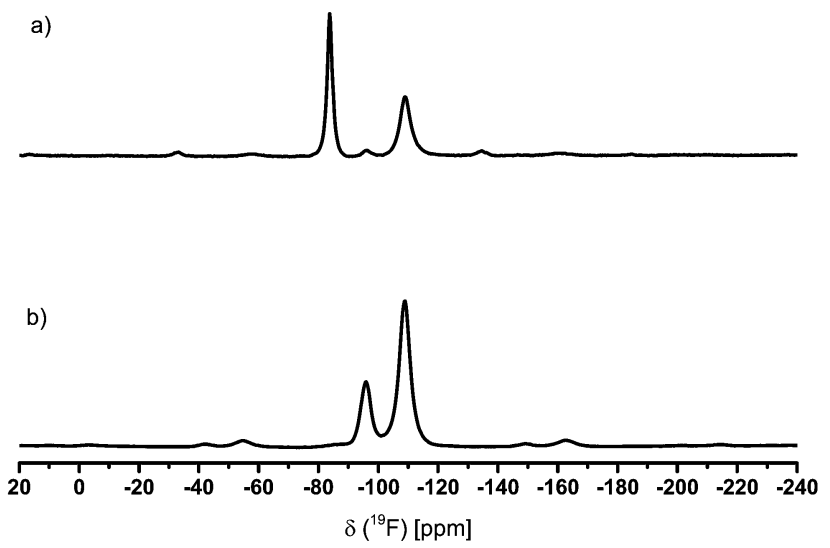

Fig. $5{ }^{19} \mathrm{~F}$ MAS NMR spectra of $\mathrm{CaF}_{2}$-xerogel prepared from $\mathrm{CaCl}_{2}$ with one equivalent of $\mathrm{HF}_{(\mathrm{EtOH})}\left(\nu_{\text {rot }}=20 \mathrm{kHz}\right)$ dried at $40{ }^{\circ} \mathrm{C}$ (a) and $\left(\nu_{\text {rot }}=19 \mathrm{kHz}\right) 600^{\circ} \mathrm{C}$ for $2 \mathrm{~h} \mathrm{(b)}$. 
relaxation time $\mathrm{T}_{2}$ between the signal at $-108 \mathrm{ppm}$ and -95 ppm in the ${ }^{19}$ F NMR spectra. According to Fig. 6 the influence of the relaxation time $\mathrm{T}_{2}$ of under-stoichiometric xerogels reveals that the intensity of the signal at -108 ppm decreases and the intensity of the signal at -95 ppm increases. Another timedependent NMR measurement was also performed with a $\mathrm{CaF}_{2}$ xerogel derived from $\mathrm{CaCl}_{2}$ with $\mathrm{H}_{2} \mathrm{O}$ as solvent (Fig. 7). In the case of $\mathrm{H}_{2} \mathrm{O}$ as solvent the ${ }^{19} \mathrm{~F}$ NMR spectra exhibit another signal at $-83 \mathrm{ppm}$ beside the main signal and the signal at -95 ppm. This signal at $-83 \mathrm{ppm}$ corresponds to $\mathrm{CaClF}$, which has the same NMR shift like the reference sample of CaClF. It is obvious that the ${ }^{19} \mathrm{~F}$ signal at about $-95 \mathrm{ppm}$ does not correspond to the CaClF species but rather to an oxide fluoride species like $\mathrm{CaF}_{2-x} \mathrm{OR}_{x}(\mathrm{R}=\mathrm{H}$, Et $)$. An explanation of the formation of an oxide fluoride species from $\mathrm{CaCl}_{2}$ in $\mathrm{EtOH}$ or in $\mathrm{H}_{2} \mathrm{O}$ with ethanolic/aqueous $\mathrm{HF}$-solution as fluorine agent could be either the preferential oxygen donation in the second coordination sphere like mentioned before or the use of only $96 \% \mathrm{CaCl}_{2}$ as precursor, which includes impurities like $\mathrm{Ca}(\mathrm{OH})_{2}$ or $\mathrm{CaClOH}$. These impurities are caused by the manufacturing process and subsequent dehydration of $\mathrm{CaCl}_{2} \cdot x \mathrm{H}_{2} \mathrm{O} .{ }^{21}$ Thus, it could be possible that after dehydration of $\mathrm{CaCl}_{2} \cdot x \mathrm{H}_{2} \mathrm{O}$ such oxygenated species are still present. If a certain amount of oxygen is incorporated in the $\mathrm{CaF}_{2}$-film, the refractive index of the film will increase, and thus, the optical properties of such films decline. However, the percentage of oxygen is not only unwanted in $\mathrm{CaF}_{2}$-films but also in ceramics due to the loss of laser oscillation as a result of the scattering at the grain boundaries, which occurs in the ceramics. ${ }^{4}$ It is known that $\mathrm{CaF}_{2}$ nanocrystals prepared by $\mathrm{CaCl}_{2}$ in EtOH with $\mathrm{NH}_{4} \mathrm{~F}$ as fluorine agent can be also obtained via co-precipitation and hydrothermal synthesis. ${ }^{22}$

However, a certain amount of oxygen is present in the $\mathrm{CaF}_{2}$ powder, which occurs from the evaporation of the precipitate. Apparently, the percentage of oxygen in the sample is induced by the drying process. Unfortunately, no ${ }^{19} \mathrm{~F}$ MAS NMR spectra
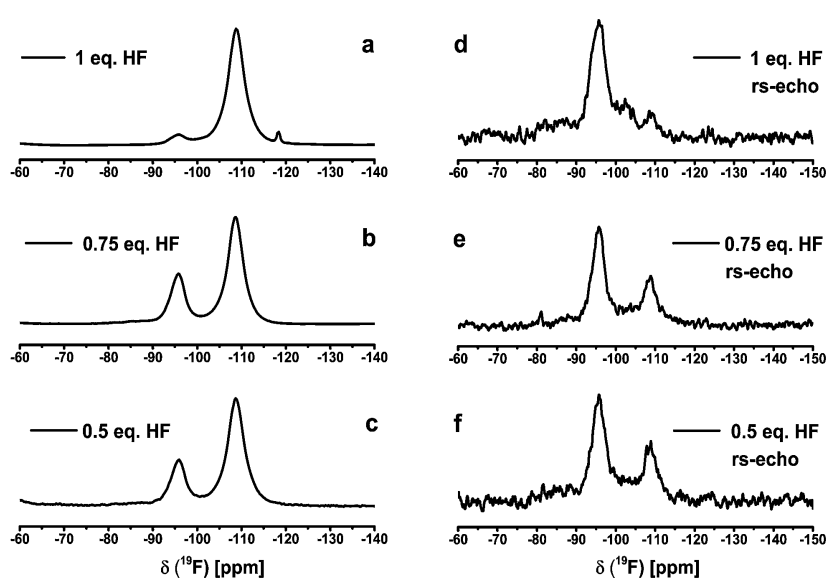

Fig. $6{ }^{19} \mathrm{~F}$ MAS NMR spectra of xerogels with $0.5\left(\nu_{\text {rot }}=19 \mathrm{kHz}\right), 0.75$ $\left(\nu_{\text {rot }}=20 \mathrm{kHz}\right)$ and 1 equivalent of $\mathrm{HF}_{(\mathrm{EtOH})}\left(\nu_{\text {rot }}=20 \mathrm{kHz}\right)$ to calcium $(a-c) D 1=5 s, N S=64$, (d) rs-echo, $L 0=20, D 1=5 s, N S=256$, (e) rsecho, $L 0=10, D 1=5 \mathrm{~s}, \mathrm{NS}=64$ and (f) $\mathrm{rs}$-echo, $\mathrm{LO}=10, \mathrm{D} 1=5 \mathrm{~s}$, $\mathrm{NS}=256$.

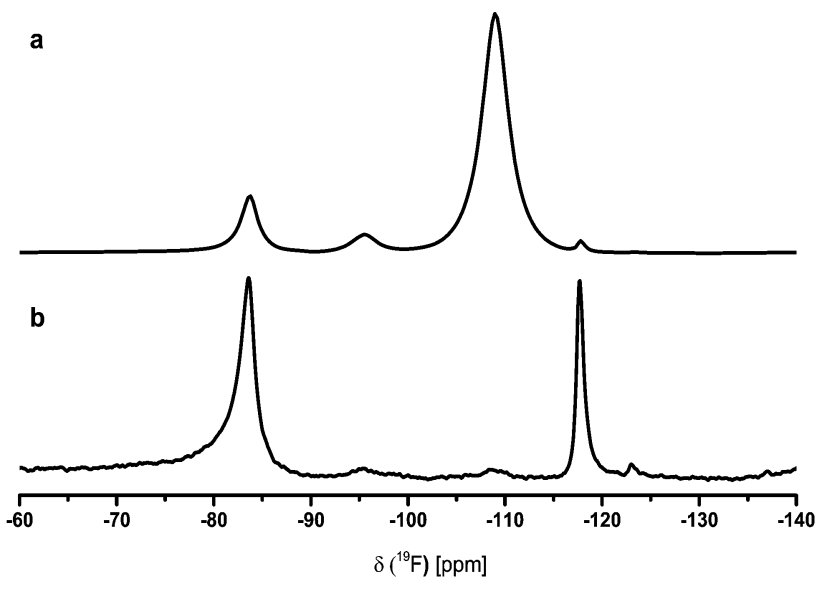

Fig. $7{ }^{19} \mathrm{~F}$ MAS NMR spectra of $\mathrm{CaF}_{2}$-xerogel derived from $\mathrm{CaCl}_{2}$ in $\mathrm{H}_{2} \mathrm{O}$ with two equivalents of $\mathrm{HF}_{(\mathrm{EtOH})}$ (a) $\nu_{\text {rot }}=25 \mathrm{kHz}, \mathrm{D} 1=5 \mathrm{~s}, \mathrm{NS}=$ 64 and (b) rs-echo, $\nu_{\text {rot }}=20 \mathrm{kHz}, \mathrm{LO}=20, \mathrm{D} 1=5 \mathrm{~s}, \mathrm{NS}=256$.

are listed in this publication, so that a comparison with the signal at $-95 \mathrm{ppm}$ of our shown spectra is not possible. The reflections in the X-ray pattern of the xerogels in Fig. 8 reveal $\mathrm{CaF}_{2}$ and CaClF. In the diffractograms as well as in the ${ }^{19} \mathrm{~F} \mathrm{NMR}$ spectra, it is notable that the CaClF species is formed at $600{ }^{\circ} \mathrm{C}$. Xerogels prepared from $\mathrm{CaCl}_{2}$ as precursor with just one equivalent of $\mathrm{HF}$ show after annealing reflections of $\mathrm{CaClF}$ (rorisite, $\mathrm{PDF}$ 24-0815) and $\mathrm{CaF}_{2}$ (fluorite, $\mathrm{PDF}$ 35-0816). In contrast, un-annealed as well as annealed xerogels obtained from stoichiometric $\mathrm{Ca}^{2+}$ to $\mathrm{HF}$ ratio show reflections of $\mathrm{CaF}_{2}$ only. Obviously, the nominal fluorine stoichiometric content in the reaction of $\mathrm{CaCl}_{2}$ with $\mathrm{HF}$ is crucial whether $\mathrm{CaClF}$ or $\mathrm{CaF}_{2}$ is formed. The powder diffractograms show that $\mathrm{CaF}_{2}$ is more crystalline in comparison to $\mathrm{MgF}_{2}$. The crystallite sizes of the un-annealed $\mathrm{CaF}_{2}$-xerogel derived from the Scherrer equation is

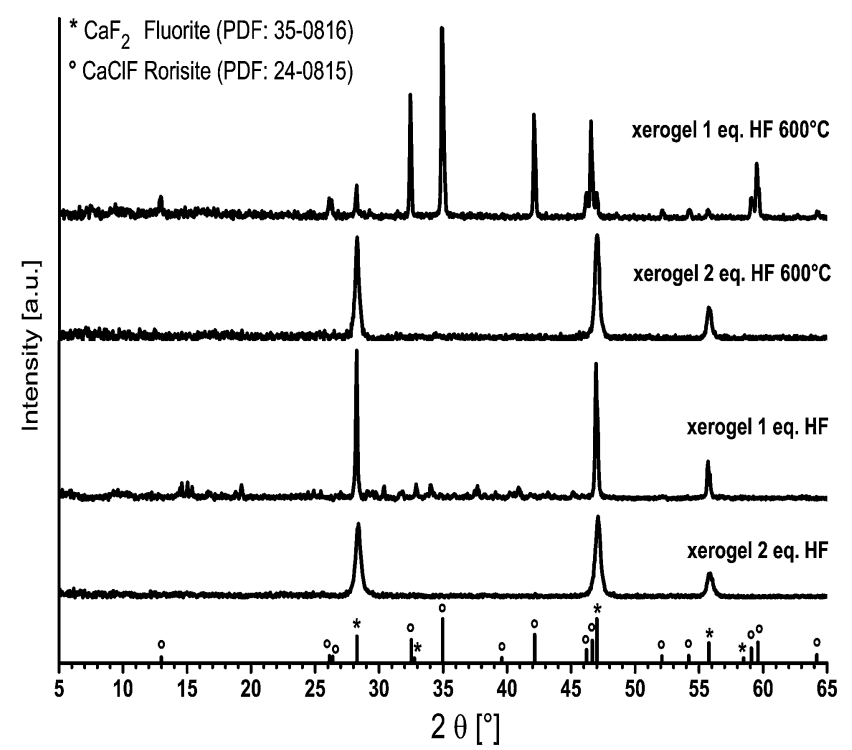

Fig. 8 X-ray diffraction patterns of un-annealed and annealed $\mathrm{CaF}_{2}$-xerogels with one and two equivalents of $\mathrm{HF}_{(\mathrm{EtOH})}$. 
about $17 \mathrm{~nm}$. In contrast, the crystallite sizes of a $\mathrm{MgF}_{2}$-xerogel annealed at $300{ }^{\circ} \mathrm{C}$ is only about $11 \mathrm{~nm} .{ }^{17}$ Moreover, the chloride concentration of the xerogels, which is given in Table 1, reveals that chloride is still present. It is apparent that un-annealed as well as annealed xerogels with a stoichiometric $\mathrm{Ca}^{2+}$ to $\mathrm{HF}$ ratio still have a small chloride percentage. It shows that the fluorination of $\mathrm{CaCl}_{2}$ is not complete. In case of one equivalent of $\mathrm{HF}$ the discrepancy of the experimentally found percentage of chloride in un-annealed and annealed xerogels is more pronounced. A plausible explanation for this effect is that the un-annealed samples contain a certain amount of water, which is caused by the hygroscopic nature of $\mathrm{CaClF} .{ }^{23} \mathrm{It}$ is evident that the deviation from the experimental to the theoretical chloride percentage results from the moisture content of the environment. $\mathrm{CaF}_{2}$-sols were used for the deposition of $\mathrm{CaF}_{2}$-films on borosilicate glass with subsequent thermal treatment at $500{ }^{\circ} \mathrm{C}$ for $15 \mathrm{~min}$. Films prepared from sols with stoichiometric fluorine content $\left(\mathrm{F}^{-} / \mathrm{Ca}^{2+}=2\right)$ were characterised regarding their optical and mechanical properties. The optical data varied depending on the $\mathrm{CaF}_{2}$-sol synthesis and post-treatment of the coated layer. E.g., the refractive index, determined by spectroscopic ellipsometry, of a $165.50 \mathrm{~nm}$ thick $\mathrm{CaF}_{2}$-film on a siliconwafer and a post-calcination at $500{ }^{\circ} \mathrm{C}$ for 15 minutes was 1.37 at $500 \mathrm{~nm}$. For $\mathrm{CaF}_{2}$-coatings on glass the reflection and absorption of the deposited $\mathrm{CaF}_{2}$-film were determined by UV-Visspectroscopy. As can be seen in Fig. 9, the reflectance at $600 \mathrm{~nm}$ reached almost nearly $0 \%$ and the absorbance of the layer between 400 and $900 \mathrm{~nm}$ is about $0 \%$ as well. Transmittance measurements of the $\mathrm{CaF}_{2}$ film and the glass substrate were not performed for this glass sample. However, AR-layers on float glass samples from different batches showed transmission values at $600 \mathrm{~nm}$ repeatedly between 98.4 to $98.7 \%$. Hence, we assume similar transmissions for this sample. Hence, the layer absorbance of $\mathrm{CaF}_{2}$ which is given in Fig. 9 holds for the transmittance of the $\mathrm{CaF}_{2}$ film on glass. It is the difference between the absorbance of the glass substrate and the absorbance of the glass substrate with $\mathrm{CaF}_{2}$ film. To illustrate the morphology of the film, the cross-section image of the $\mathrm{CaF}_{2}$-film derived from high resolution scanning electron microscopy (HR-SEM) is shown in Fig. 10. The measured thickness of the film is approximately $170 \mathrm{~nm}$, and thus, corresponds very well to that determined by ellipsometry. This is in good agreement with the conditions of antireflective coatings. The diameter of the particles is between 10 and $30 \mathrm{~nm}$. This corresponds well with the crystallite sizes of the xerogel determined by XRD. Furthermore, the film is very porous due to the pores, which completely proceed through the whole film. Apparently, if

Table 1 Chloride percentage of the xerogels by elemental analysis

\begin{tabular}{lcc}
\hline Xerogel & Theoretical Cl [\%] & Experimental Cl [\%] \\
\hline 1 eq. HF after $40{ }^{\circ} \mathrm{C}$ & 37.50 & 23.42 \\
1 eq. HF after $600^{\circ} \mathrm{C}$ & 37.50 & 34.43 \\
2 eq. HF after $40{ }^{\circ} \mathrm{C}$ & 0.0 & 4.16 \\
2 eq. HF after $600^{\circ} \mathrm{C}$ & 0.0 & 2.21
\end{tabular}

Fig. 9 Reflectance and absorption spectra of the $\mathrm{CaF}_{2}$-film annealed at $500{ }^{\circ} \mathrm{C}$ by UV-Vis-spectroscopy and refractive index of $\mathrm{CaF}_{2}$ film and $\mathrm{CaF}_{2}$ bulk ${ }^{24}$ according to the wavelength.

chloride is still present in the film, a certain amount of CaClF might be formed. Hence, the sintering process of a CaClFcontaining $\mathrm{CaF}_{2}$-film might be rendered, which is reflected by the high porosity as well mechanical abrasion (Fig. 11). Another fact causing creation of porosity could be also the release of the organic solvent together with $\mathrm{HCl}$ formed by the reaction of $\mathrm{HF}$ with $\mathrm{CaCl}_{2}$. Thus, these pores filled with air $\left(n_{0} \approx 1.0\right)$ are the reason for the low refractive index of the $\mathrm{CaF}_{2}-$ film. Similar porous coating films are well known for $\mathrm{SiO}_{2}$-films on glass. ${ }^{25,26}$ Since $\mathrm{CaF}_{2}$ exhibits a lower refractive index than $\mathrm{SiO}_{2}$, it was expected that $\mathrm{CaF}_{2}$-AR-layers with lower porosity but equally good refractive indices possess higher mechanical stability. Therefore, mechanical abrasion of the films was tested too. For that purpose, the $\mathrm{CaF}_{2}$-films annealed at $500{ }^{\circ} \mathrm{C}$ were subjected to the Crockmeter test. Fig. 11 is showing the $\mathrm{CaF}_{2}$-film before and after abrasion with felt and steel wool. After 100 cycles with felt and 25 cycles with steel wool the film has only a slight scratch track. Under these conditions, the films are almost

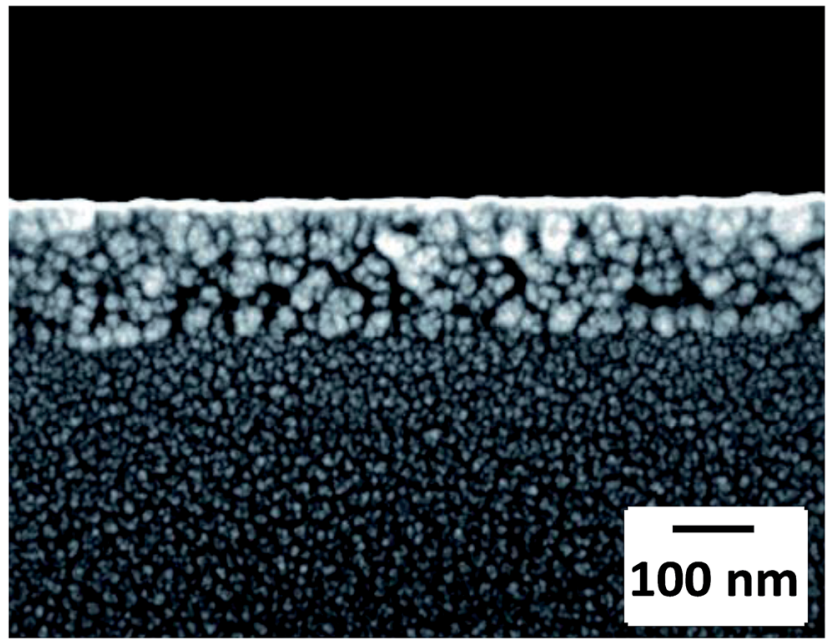

Fig. 10 Cross-section image of the $\mathrm{CaF}_{2}-$ film annealed at $500{ }^{\circ} \mathrm{C}$ by HR-SEM 


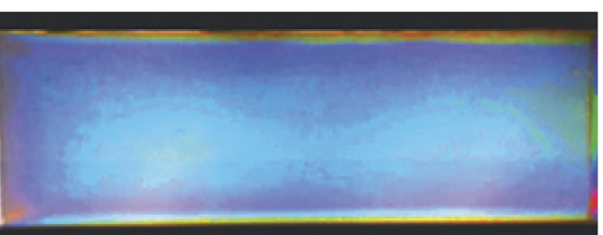

felt

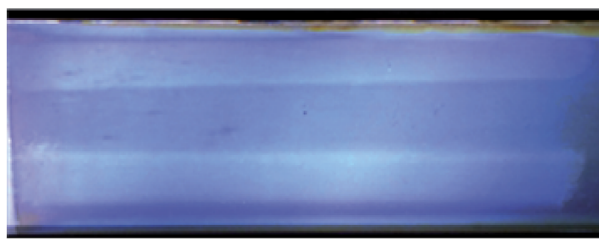

Fig. 11 Photographs of the $\mathrm{CaF}_{2}$-film on borosilicate glass substrate $\left(20 \times 4 \mathrm{~cm}^{2}\right)$ before and after abrasion with 100 cycles of felt and 25 cycles of steel wool by Crockmeter test. The sample has been treated at $500{ }^{\circ} \mathrm{C}$ for $15 \mathrm{~min}$ prior the analysis.

robust against abrasion. Just the very surface near region seems to show some little damages without losing the optical performance. There is no visual difference in the abrasion with felt or steel wool. In conclusion, the mechanical stability of $\mathrm{CaF}_{2}$-films is better than that of other $\mathrm{CaF}_{2}$-films, which were derived from calcium acetate as mentioned above. All in all, the $\mathrm{CaF}_{2}$-films show not only excellent optical performance, but show at the same time also good mechanical stability.

\section{Conclusions}

The synthesis of $\mathrm{CaF}_{2}$-sols containing nanoscopic particles was successfully performed by reaction of $\mathrm{CaCl}_{2}$ as inexpensive precursor with anhydrous $\mathrm{HF}$ in ethanol. Addition of up to 5 mol\% TMOS or TEOS after fluorination always causes a rapid formation of a transparent sol with small particle diameter in the range of 10 to $20 \mathrm{~nm}$. This coating solution is stable for several weeks. No sedimentation was observed. TMOS not only causes a fast clearing up of the sol but also stabilizes the $\mathrm{CaF}_{2}$ particles in the sol. Apparently, addition of TMOS leads to a deagglomeration of the particles probably due to the reaction with the traces of un-reacted $\mathrm{HF}$ in the reaction system. We speculate that the electrostatic repulsion of the particles is changed due to the formation of $\mathrm{Si}(\mathrm{OR})_{4-x} \mathrm{~F}_{x}$-species - even the formation of $\mathrm{SiF}_{4}$ - as intermediate product cannot be ruled out. Since these are strong Lewis acids, the formation of a $\mathrm{CaSiF}_{6}$ species might be favoured. Further investigations are necessary to study the real rule of TMOS in the $\mathrm{CaF}_{2}$ system. We also evidenced the formation of $\mathrm{CaClF}$ at $600{ }^{\circ} \mathrm{C}$ beside the formation of an oxide fluoride species during the fluorination. Interestingly, the formation of $\mathrm{CaClF}$ is also favoured by using $\mathrm{H}_{2} \mathrm{O}$ as solvent with two equivalents of aqueous HF-solution and subsequent drying at room temperature. The observation for the oxide fluoride species was not only recorded for $\mathrm{CaCl}_{2}$ as precursor but also for other calcium precursors like calcium bromide or calcium oxide. The percentage of oxygen in the samples could be explained by dehydration of $\mathrm{CaCl}_{2} \cdot x \mathrm{H}_{2} \mathrm{O}$. It is also known that $\mathrm{CaF}_{2}$ nanocrystals derived from $\mathrm{CaCl}_{2}$ in $\mathrm{EtOH}$ with $\mathrm{NH}_{4} \mathrm{~F}$, which are prepared by co-precipitation and solvothermal technique, possess impurities of oxygen too. That could be a problem for laser applications because it leads to optical scattering losses, and hence, prohibit laser oscillation. Hence, it is difficult to completely exclude oxygen in $\mathrm{CaF}_{2}$ nanocrystals by sol-gel as well as other synthesis techniques. The $\mathrm{CaF}_{2}$-films exhibit excellent antireflective properties. The mechanical resistance of such films compared to $\mathrm{CaF}_{2}$-films, which were derived from calcium acetate, is significantly better. Only corresponding $\mathrm{MgF}_{2}$-films show marginal better mechanical resistance. It is worth noting that a further improvement of the mechanical properties of these antireflective layers is essential for applications, where a mechanical resistance is indispensable. However, due to the lower solubility as compared to $\mathrm{MgF}_{2}$, $\mathrm{CaF}_{2}$ is an interesting alternative candidate for the manufacture of antireflective coatings.

\section{Acknowledgements}

This work was financed by the graduate school GRK 1582 "Fluorine as a Key Element" by the Deutsche Forschungsgemeinschaft (DFG). Furthermore, we thank Sigrid Benemann (Federal Institute for Materials Research and Testing, Berlin) for HR-SEM measurements, Dr Gianvito Caputo (HU-Berlin) for TEM measurements, Dr Andrea Zehl (HU-Berlin) for elemental analysis, PD Dr Gudrun Scholz for the discussion of MAS NMR spectra and Dr Birgit Lintner (Prinz Optics $\mathrm{GmbH}$ ) for UV-Vis-spectroscopy measurements.

\section{Notes and references}

1 I. H. Malitson, Appl. Opt., 1963, 2, 1103-1107.

2 P. A. Popov, K. V. Dukel'skii, I. A. Mironov, A. N. Smirnov, P. L. Smolyanskii, P. P. Fedorov, V. V. Osiko and T. T. Basiev, Dokl. Phys., 2007, 52, 7-9.

3 I. Nicoara, M. Stef and A. Pruna, J. Cryst. Growth, 2008, 310, 1470-1475.

4 A. Ikesue and Y. L. Aung, Nat. Photonics, 2008, 2, 721-727.

5 M. J. Dodge, Appl. Opt., 1984, 23, 1980-1985.

6 H. K. Pulker, Coating on glass, Elsevier Amsterdam, 1999.

7 C. Barta, F. Fendrych, K. Recker, A. Triska and F. Wallrafen, Cryst. Res. Technol., 1990, 25, 1287-1298.

8 M. Tada, S. Fujihara and T. Kimura, J. Mater. Res., 1999, 14, 1610-1616.

9 S. Fujihara, Y. Kadota and T. Kimura, J. Sol-Gel Sci. Technol., 2002, 24, 147-154.

10 E. Kemnitz, U. Gross, S. Rudiger and C. S. Shekar, Angew. Chem., Int. Ed., 2003, 42, 4251-4254.

11 R. Sokoll, H. J. Tiller and T. Hoyer, J. Electrochem. Soc., 1991, 138, 2150-2153.

12 F. Sayilkan, M. Asilturk, H. Sayilkan, Y. Onal, M. Akarsu and E. Arpac, Turk. J. Chem., 2005, 29, 697-706.

13 B. E. Yoldas, Am. Ceram. Soc. Bull., 1975, 54, 289-290.

14 Y. L. Diao, W. P. Walawender, C. M. Sorensen, K. J. Klabunde and T. Ricke, Chem. Mater., 2002, 14, 362-368.

15 N. Y. Turova, E. P. Turevskaya, V. G. Kessler, A. I. Yanovsky and Y. T. Struchkov, J. Chem. Soc., Chem. Commun., 1993, 21-23. 
16 A. Rehmer, in Department of chemistry, HumboldtUniversität zu Berlin, 2012, p. 74.

17 J. Noack, K. Scheurell, E. Kemnitz, P. Garcia-Juan, H. Rau, M. Lacroix, J. Eicher, B. Lintner, T. Sontheimer, T. Hofmann, J. Hegmann, R. Jahn and P. Lobmann, J. Mater. Chem., 2012, 22, 18535-18541.

18 G. Scholz, C. Stosiek, J. Noack and E. Kemnitz, J. Fluorine Chem., 2011, 132, 1079-1085.

19 M. Karg, G. Scholz, R. Konig and E. Kemnitz, Dalton Trans., 2012, 41, 2360-2366.

20 D. A. Wenz, I. Johnson and R. D. Wolson, J. Chem. Eng. Data, 1969, 14, 250-252.
21 K. M. Allal, J. C. Doliginier and G. Martin, Oil Gas Sci. Technol., 1997, 52, 361-368.

22 C. Pandurangappa, B. N. Lakshminarasappa and B. M. Nagabhushana, J. Alloys Compd., 2010, 489, 592-595.

23 H. P. Beck, J. Solid State Chem., 1976, 17, 275-282.

24 Schott Optical Glass Catalogue on August 2010.

25 Y. Liu, W. Ren, L. Y. Zhang and X. Yao, Thin Solid Films, 1999, 353, 124-128.

26 N. K. Park, Y. S. Kim, M. J. Kim, T. J. Lee, S. H. Lee and S. H. Lee, J. Nanosci. Nanotechnol., 2013, 13, 7493-7497. 